\title{
Agouti-Related Protein Neuron Circuits That Regulate Appetite
}

\author{
Scott M. Sternson ${ }^{a}$ Deniz Atasoy ${ }^{b, c}$ \\ a Janelia Research Campus, HHMI, Ashburn, Va., USA; ${ }^{b}$ Department of Physiology, School of Medicine, and ${ }^{\mathrm{c}}$ Research \\ Center for Regenerative and Restorative Medicine (REMER), Istanbul Medipol University, Istanbul, Turkey
}

\section{Key Words}

Agouti-related protein · Appetite · Ghrelin

\begin{abstract}
New tools for mapping and manipulating molecularly defined neural circuits have improved the understanding of how the central nervous system regulates appetite. Studies that focused on Agouti-related protein neurons, a starvation-sensitive hypothalamic population, have identified multiple circuit elements that can elicit or suppress feeding behavior. Distinct axon projections of this neuron population point to different circuits that regulate long-term appetite, short-term feeding, or visceral malaise-mediated anorexia. Here, we review recent studies examining these neural circuits that control food intake.

(c) 2014 S. Karger AG, Basel
\end{abstract}

\section{Introduction}

A longstanding goal of neuroscience is to understand the relationship between brain function and behavioral states such as hunger [1-3]. Appetite is controlled by multiple circuits that are comprised of distinct molecularly defined neuron populations $[4,5]$. These networks integrate peripheral signals of metabolic and visceral state (e.g., hormones and metabolites) and either coordinate or suppress behavioral responses to seek and consume food. Much of the recent work has focused on the circuits involving Agouti-related protein (AGRP)-expressing neurons, a small molecularly defined population in the hypothalamic arcuate nucleus (ARC) that senses circulating signals of the energetic status. AGRP neurons are activated by hormonal signals of energy deficit (e.g., ghrelin) $[6,7]$ and are inhibited by signals of energy surfeit (e.g., leptin) $[7,8]$. Optogenetic and chemogenetic activation of AGRP neuron firing leads to voracious food seeking and consumption behaviors within minutes [9-11]. Conversely, AGRP neuron ablation or chemogenetic inhibition results in appetite suppression [10, 12]. Bidirectional control of feeding behavior by AGRP neurons makes them an attractive entry point to investigate the neural circuits that regulate feeding behavior, and, using new tools, multiple pathways have been identified (fig. 1; table 1). Here we review emerging insights into the neural control of appetite.

\section{Molecular Mediators of Appetite}

AGRP neurons release a number of molecules that rapidly elicit intense food consumption when injected into the brain: AGRP [13], neuropeptide Y (NPY) [14],

\section{KARGER}

E-Mail karger@karger.com

www.karger.com/nen
(C) 2014 S. Karger AG, Basel

0028-3835/14/1003-0095\$39.50/0
Scott M. Sternson

Janelia Research Campus, HHMI 19700 Helix Dr.

Ashburn, VA 20147 (USA)

E-Mail sternsons@janelia.hhmi.org 


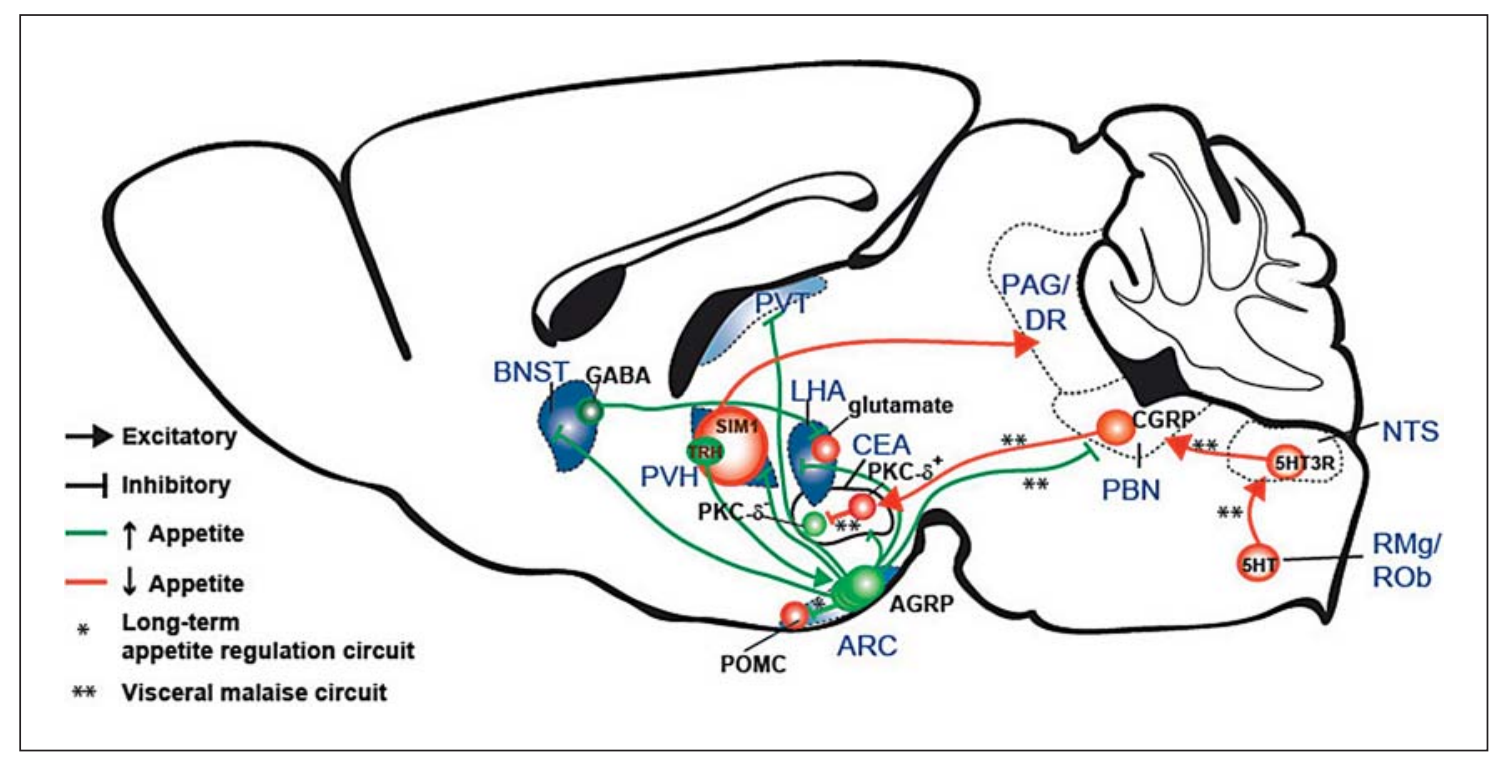

Fig. 1. Summary diagram illustrating cell types and circuits that influence appetite. Blue shading represents sites associated with AGRP neuron-evoked food intake. Based on anatomical studies, AGRP neurons are shown as separate subpopulations defined by their axon projection sites. $\mathrm{RMg}=$ Raphe magnus nucleus; $\mathrm{ROb}=\mathrm{raphe}$ obscurus nucleus; SIM1 = single-minded homolog 1; DR = dorsal raphe.

and $\gamma$-aminobutyric acid (GABA) [15]. The relative role of these molecules for AGRP neuron-evoked feeding has recently been examined. The results of several experiments indicate that NPY and GABA mediate initiation of eating within minutes of elevated AGRP neuron activity, whereas the neuropeptide AGRP regulates feeding over longer timescales. Increased food intake resulting from optogenetic or chemogenetic activation (fig. 2) of AGRP neurons was suppressed by either an NPY $1 \mathrm{R}$ antagonist or a $\mathrm{GABA}_{\mathrm{A}}$ receptor antagonist microinjected in the paraventricular hypothalamic nucleus (PVH) [11]. This showed that AGRP neurons require both NPY and GABA signaling to elicit acute feeding responses. A related result using mutant mice confirmed this finding, with some noteworthy differences. Chemogenetic activation of AGRP neurons (fig. 2c) in either $N p y^{-/-}$mice or in mice lacking GABA in AGRP neurons each rapidly evoked feeding behavior [16]. One difference with the pharmacological analysis described above was that either NPY or GABA alone appeared sufficient for acute feeding. An explanation for this apparent discrepancy is indicated by a closer evaluation of $\mathrm{Npy}^{-/-}$mice in which electrophysiological analysis showed dramatic compensatory upregulation of AGRP neuron synaptic output: connectivity and GABA release probability (fig. 3) [11]. Therefore, it appears that GABA and NPY are both required for acute feeding, as revealed by pharmacological inactivation experiments, but they likely compensate for one another in mutant mouse models.

What is the role for the AGRP neuropeptide released by AGRP neurons? AGRP inhibits melanocortin receptors, which leads to increased food intake and body weight. However, AGRP neuron photostimulation still rapidly elicits feeding behavior in $A^{y}$ mutant mice [9], in which melanocortin receptors are constitutively blocked. This indicated that the AGRP neuropeptide was not required for acute AGRP neuron-evoked feeding behavior. Interestingly though, activation of AGRP neurons lacking both GABA and NPY increased feeding with a delay of several hours, and this was not observed if melanocortin receptor 4 was absent [16]. Together, these results from AGRP neuron activation studies revealed that unlike NPY and GABA, which mediate acute feeding, the neuropeptide AGRP and its interaction with melanocortin receptors are involved in long-term regulation of feeding behavior.

\section{Circuit for Long-Term Regulation of Food Intake}

Appetite is regulated on timescales of minutes for the execution of feeding behavior as well as over longer timescales associated with maintaining energy homeostasis. 


\begin{tabular}{|c|c|c|c|}
\hline PRE-SYNAPTIC SITE $\stackrel{\text { CELL TYPE }}{\longrightarrow}$ POST-SYNAPTIC SITE (Actuator) & Food intake & Notes & References \\
\hline $\operatorname{ARC}^{\text {AGRP }}($ ChR2 $\uparrow)$ & $\uparrow$ & Somatic photostimulation & [9] \\
\hline $\mathrm{ARC} \stackrel{\mathrm{AGRP}}{\rightarrow} \mathrm{PVH} \quad(\mathrm{ChR} 2 \uparrow)$ & $\uparrow$ & Projection photostimulation & [11] \\
\hline $\mathrm{ARC}^{\mathrm{AGRP}} \stackrel{\mathrm{PVH}}{\rightarrow}(\mathrm{ChR} 2 \uparrow)+\mathrm{PVH}^{\mathrm{Sim} 1}(\mathrm{ChR} 2 \uparrow)$ & - & $\begin{array}{l}\text { Dual activation; projection photostimulation(ARC - AGRP over } \\
\text { PVH) and somatic photostimulation (Sim1) }\end{array}$ & [11] \\
\hline $\operatorname{ARC}^{\text {AGRP }}(\mathrm{ChR} 2 \uparrow)+\mathrm{ARC}^{\mathrm{AGRP}} \stackrel{\text { PVH }}{\rightarrow}(\mathrm{hM} 4 \mathrm{Di} \downarrow)$ & $\uparrow$ & $\begin{array}{l}\text { Simultaneous activation and inhibition, somatic photostimulation } \\
\text { (ARC-AGRP) and projection chemoinhibition (ARC-AGRP over PVH) }\end{array}$ & [32] \\
\hline ARC $\stackrel{\text { AGRP }}{\rightarrow}$ PVH $\quad(\mathrm{ChR} 2 \uparrow)+\mathrm{PVH}^{\text {Oxt }}(\mathrm{ChR} 2 \uparrow)$ & - & $\begin{array}{l}\text { Dual activation by photostimulation; projection activation (ARC } \\
\text { - AGRP over PVH) and somatic stimulation (PVH-Oxytocin) }\end{array}$ & [11] \\
\hline$A R C \stackrel{\text { AGRP }}{\rightarrow} \mathrm{PVH}_{\left(\mathrm{bl-GABA} A_{A} \mathrm{R}\right)}(\mathrm{ChR2 \uparrow )}$ & - & $\begin{array}{l}\text { Projection photostimulation (ARC-AGRP over PVH) while } \\
\text { blocking PVH - GABA } \text { receptors }\end{array}$ & [11] \\
\hline ARC $\stackrel{\text { AGRP }}{\rightarrow} \mathrm{PVH}_{(\mathrm{bl}-\mathrm{Y} 1 \mathrm{R})} \quad(\mathrm{ChR} 2 \uparrow)$ & - & $\begin{array}{l}\text { Projection photostimulation (ARC-AGRP over PVH) while } \\
\text { blocking PVH - Y1R receptors }\end{array}$ & [11] \\
\hline $\left.\left.\operatorname{ARC}_{(\mathrm{AGRP}}{ }_{(\mathrm{hM} 3 \mathrm{Dq} \uparrow} \uparrow\right)+\mathrm{PVH}_{(\mathrm{bl}-\mathrm{GABA}} \mathrm{R}\right)$ & $\uparrow$ & $\begin{array}{l}\text { Systemic chemogenetic activation by I.P. injection of CNO } \\
\text { (ARC-AGRP) while blocking PVH - GABA receptors }\end{array}$ & [11] \\
\hline 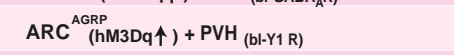 & $\uparrow$ & $\begin{array}{l}\text { Systemic chemogenetic activation by I.P. injection of CNO } \\
\text { (ARC-AGRP) while blocking PVH - Y1R receptors }\end{array}$ & [11] \\
\hline $\mathrm{ARC}^{\mathrm{AGRP}} \rightarrow \mathrm{BNST}(\mathrm{ChR} 2 \uparrow)$ & $\uparrow$ & Projection photostimulation & [21] \\
\hline ARC $\stackrel{\text { AGRP }}{\rightarrow}$ LHA $\quad($ ChR2 $\uparrow)$ & $\uparrow$ & Projection photostimulation & [21] \\
\hline ARC $\stackrel{\text { AGRP }}{\rightarrow}$ PVT $\quad($ ChR2 $\uparrow)$ & $\uparrow$ & Projection photostimulation & [21] \\
\hline $\mathrm{ARC} \stackrel{\text { AGRP }}{\rightarrow} \mathrm{CEA} \quad(\mathrm{ChR} 2 \uparrow)$ & - & Projection photostimulation & [21] \\
\hline $\mathrm{ARC} \stackrel{\text { AGRP }}{\rightarrow}$ PBN $(\mathrm{ChR2 \uparrow )}$ & - & Projection photostimulation & [11] \\
\hline $\mathrm{ARC}^{\mathrm{AGRP}} \stackrel{\mathrm{PAG}}{\rightarrow}(\mathrm{ChR} 2 \uparrow)$ & - & Projection photostimulation & [21] \\
\hline $\operatorname{ARC}^{\text {AGRP }}(\mathrm{hM} 3 \mathrm{Dq} \uparrow)$ & $\uparrow$ & Systemic chemogenetic activation by I.P. injection of CNO & [10] \\
\hline $\mathrm{ARC}_{\triangle \mathrm{NPY}, \triangle \mathrm{MC} 4 \mathrm{R}}^{\mathrm{AGRP}}(\mathrm{hM} 3 \mathrm{Dq} \uparrow)$ & $\uparrow$ & $\begin{array}{l}\text { Systemic chemogenetic activation by } 1 . P . \\
\text { injection of CNO in NPY+MC4R deficient mice }\end{array}$ & [16] \\
\hline $\mathrm{ARC}_{\triangle \mathrm{VGAT}, \triangle \mathrm{MC} 4 \mathrm{R}}^{\mathrm{AGRP}}(\mathrm{hM} 3 \mathrm{Dq} \uparrow)$ & $\uparrow$ & $\begin{array}{l}\text { Systemic chemogenetic activation by I.P. injection of CNO in } \\
\text { VGAT KO (AGRP-neuron specific) and MC4R deficient mice }\end{array}$ & [16] \\
\hline $\mathrm{ARC}_{\triangle \mathrm{VGAT}, \triangle \mathrm{NPY}}^{\mathrm{AGRP}}(\mathrm{hM} 3 \mathrm{Dq} \uparrow)$ & - & $\begin{array}{l}\text { Systemic chemogenetic activation by I.P. injection of CNO in VGAT KO } \\
\text { (AGRP- neuron specific) and NPY deficient mice, } 24 \mathrm{~h} \text { feeding persists }\end{array}$ & [16] \\
\hline $\mathrm{ARC}_{\triangle \mathrm{VGGAT}, \triangle \mathrm{NPY}, \triangle \mathrm{MC} 4 \mathrm{R}}^{\mathrm{AGRP}}(\mathrm{hM} 3 \mathrm{Dq} \uparrow)$ & - & $\begin{array}{l}\text { Systemic activation by I.P. injection of CNO in VGAT KO (AGRP. } \\
\text { neuron specific) and NPY + MC4R deficient mice, } 24 \mathrm{~h} \text { feeding persists }\end{array}$ & [16] \\
\hline $\operatorname{ARC}^{\text {AGRP }}(\mathrm{hM} 4 \mathrm{Di} \downarrow)$ & $\downarrow$ & Systemic chemogenetic inhibition by I.P. injection of CNO & [10] \\
\hline $\operatorname{ARC}^{\text {AGRP }}(\operatorname{ChR2} \uparrow)+\operatorname{ARC}^{\text {POMC }}(\mathrm{ChR} \uparrow)$ & $\uparrow$ & Dual activation by somatic photostimulation & [11] \\
\hline $\operatorname{ARC}^{\text {POMC }}(\mathrm{ChR} 2 \uparrow)$ & - & Somatic photostimulation. $24 \mathrm{~h}$ food intake decreases. & [9] \\
\hline $\operatorname{ARC}^{\text {POMC }}(\mathrm{hM} 3 \mathrm{Dq} \uparrow)$ & - & $\begin{array}{l}\text { Systemic chemogenetic activation by I.P. injection of } \\
\text { CNO, } 24 \mathrm{~h} \text { food intake decreases. }\end{array}$ & [18] \\
\hline $\operatorname{ARC}^{\text {POMC }}(\mathrm{hM} 4 \mathrm{Di} \downarrow)$ & - & $\begin{array}{l}\text { Systemic chemoinhibition by I.P. injection of CNO, } 24 \\
\text { h food intake increases. }\end{array}$ & [11] \\
\hline NTS $^{\text {POMC }}($ (hM3Dq $\uparrow)$ & $\downarrow$ & Systemic chemogenetic activation by I.P. injection of CNO & [18] \\
\hline $\mathrm{PVH}^{\text {SIM1 }}$ (hM4Di $\left.\downarrow\right)$ & $\uparrow$ & Systemic chemogenetic activation by I.P. injection of CNO & {$[11]$} \\
\hline $\left.\mathrm{PVH}^{\mathrm{TRH}}{ }_{(\mathrm{hM} 3 \mathrm{Dq} \uparrow} \uparrow\right)$ & $\uparrow$ & Systemic chemogenetic activation by I.P. injection of CNO & [31] \\
\hline $\mathrm{PVH}^{\text {PACAP }}(\mathrm{hM} 3 \mathrm{Dq} \uparrow)$ & $\uparrow$ & Systemic chemogenetic activation by I.P. injection of CNO & [31] \\
\hline $\mathrm{PVH}^{\mathrm{SIM} 1} \rightarrow$ PAG $(\mathrm{hM} 4 \mathrm{Di})$ & $\uparrow$ & Projection chemogenetic inhibition by local CNO injection & [32] \\
\hline PVH $\stackrel{\text { SIM1 }}{\rightarrow}$ PBN (hM4Di $\downarrow)$ & - & Projection chemogenetic inhibition by local CNO injection & [32] \\
\hline PVH $\stackrel{\text { SIM1 }}{\rightarrow}$ NTS (hM4Di $\downarrow)$ & - & Projection chemogenetic inhibition by local CNO injection & [32] \\
\hline BNST $\stackrel{\text { VGAT }}{\rightarrow}$ LHA $\quad($ ChR2 $\uparrow)$ & $\uparrow$ & Projection photostimulation & [29] \\
\hline BNST $\stackrel{\text { VGAT }}{\rightarrow}$ LHA $($ eArch $\downarrow)$ & $\downarrow$ & Projection silencing by photoinhibition & [29] \\
\hline LHA $^{\text {VGLUT2 }}$ (ChR2 $\left.\uparrow\right)$ & $\downarrow$ & Somatic photostimulation & [29] \\
\hline PBN $^{\text {CGRP }} \quad($ ChR2 $\uparrow)$ & $\downarrow$ & Somatic photostimulation & [35] \\
\hline PBN $^{\text {CGRP }}(\mathrm{hM} 3 \mathrm{Dq} \uparrow)$ & $\downarrow$ & Systemic chemogenetic activation by I.P. injection of CNO & [35] \\
\hline PBN $^{\text {CGRP }}$ (hM4Di $\left.\downarrow\right)$ & - & Systemic chemogenetic inhibition by I.P. injection of CNO & [35] \\
\hline PBN $\stackrel{\text { CGRP }}{\rightarrow}$ CEA $($ ChR2 $\uparrow)$ & $\downarrow$ & Projection photostimulation & [35] \\
\hline PBN $\stackrel{\text { CGRP }}{\rightarrow}$ BNST (ChR2 $\uparrow)$ & - & Projection photostimulation & [35] \\
\hline $\mathrm{CEA}^{\mathrm{PKC}-\delta+}(\mathrm{ChR} 2 \uparrow)$ & $\downarrow$ & Somatic photostimulation & [36] \\
\hline $\mathrm{CEA} \stackrel{\mathrm{PKC}-\delta+}{\rightarrow} \mathrm{PBN}(\mathrm{ChR} 2 \uparrow)$ & - & Projection photostimulation & {$[36]$} \\
\hline $\mathrm{CEA} \stackrel{\mathrm{PKC}-\delta+}{\rightarrow} \mathrm{BNST}(\mathrm{ChR} 2 \uparrow)$ & - & Projection photostimulation & [36] \\
\hline $\operatorname{CEA}_{\left(\mathrm{bl}-\mathrm{GABA}_{\mathrm{A}} \mathrm{R}\right)}^{\mathrm{PKC} \delta+} \quad(\mathrm{ChR2 \uparrow})$ & - & $\begin{array}{l}\text { Somatic photostimulation (CEA-PKC } \delta+\text { ) while blocking } \\
\text { CEA- GABA } A_{A} \text { receptors }\end{array}$ & [36] \\
\hline CEA $^{\text {PKC-òे }}($ hM4Di $\downarrow)$ & $\uparrow$ & Systemic chemogenetic inhibition by I.P. injection of CNO & [36] \\
\hline CEA $^{\text {PKC- } \delta+}($ NpHR $\downarrow)$ & $\uparrow$ & Somatic photoinibition & [36] \\
\hline $\mathrm{CEA}^{\text {PKC-8- }}(\mathrm{ChR2} \uparrow)$ & - & Somatic photostimulation & [36] \\
\hline CEA $^{\text {Tac2 }}$ (ChR2 $\left.\uparrow\right)$ & - & Somatic photostimulation & [36] \\
\hline CEA ${ }^{\text {CRF }}(\operatorname{ChR} 2 \uparrow)$ & - & Somatic photostimulation & {$[36]$} \\
\hline
\end{tabular}

Table 1. Cell type-specific neuronal circuit manipulations that regulate food intake
Neuroendocrinology 2014;100:95-102 DOI: $10.1159 / 000369072$
AGRP Neuron Circuits That Regulate Appetite 


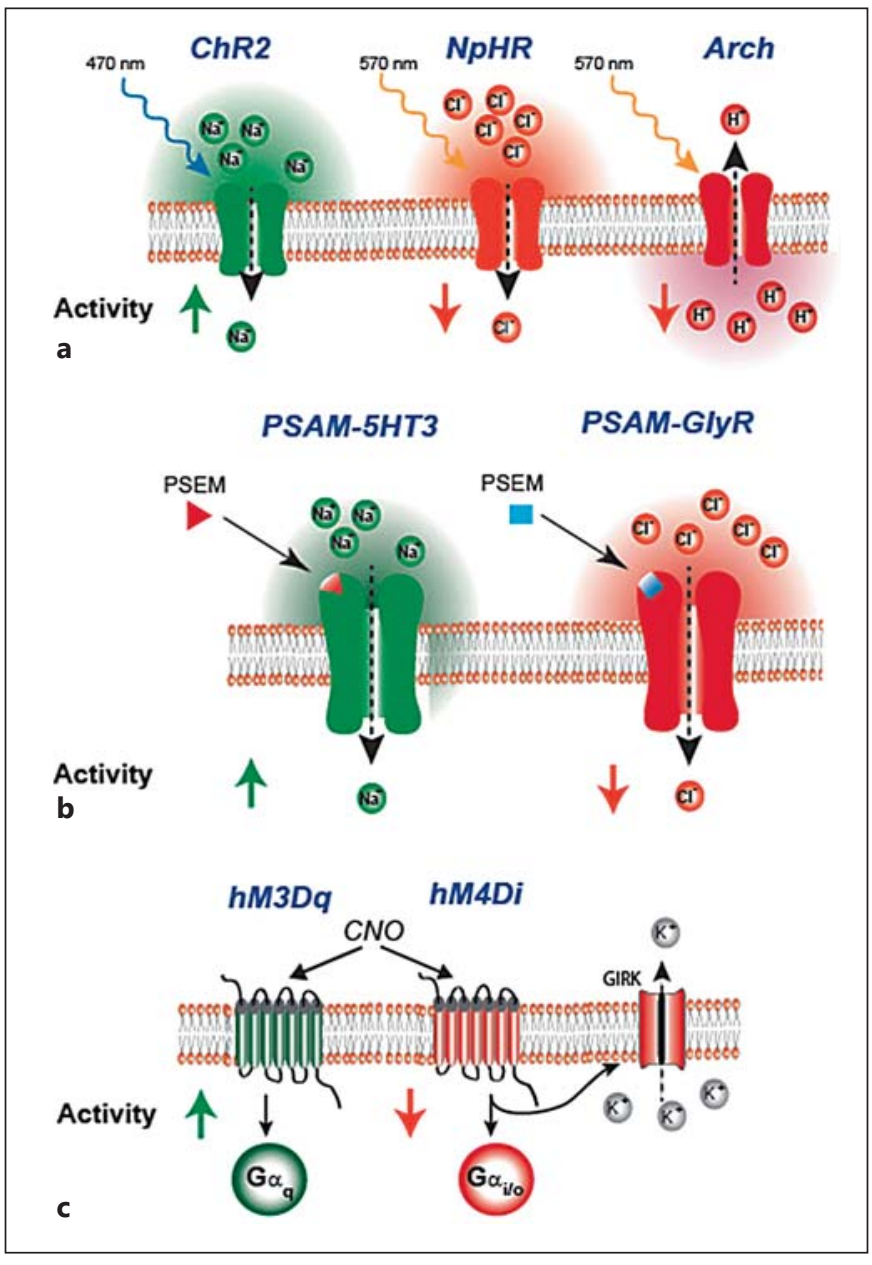

Fig. 2. Optogenetic [37] and chemogenetic [38] tools for neuronal activity manipulation. a Rapid reversible manipulation of neuronal membrane potential can be achieved using optogenetic tools. Channelrhodopsin-2 (ChR2) is a cation channel activated by blue light, which depolarizes neurons in response to blue light to trigger action potentials with millisecond precision. Halorhodopsin (NpHR) and Archaerhodopsin (Arch) are activated by yellow wavelengths and pump chloride ions and protons, respectively. These channels hyperpolarize neurons and inhibit activity with millisecond precision. b, c Variations on chemogenetic silencing tools; direct manipulation of ionic conductances (b) or G-proteincoupled intracellular pathways (c). Chimeric PSAM (pharmacologically selective actuator module)-based ligand gated ion channels: PSAM-5HT3 or PSAM-GlyR acutely modulate cation or chloride membrane conductances when activated by their cognate synthetic ligands (PSEMs = pharmacologically selective effector molecules), enabling rapid reversible activation or inhibition of neuronal activity, respectively. Similarly, engineered variants of human muscarinic acetylcholine receptors, hM3Dq and hM4Di, have reduced acetylcholine sensitivity but are responsive to an otherwise inert synthetic ligand, Clozapine-N-oxide (CNO). Delivery of $\mathrm{CNO}$ activates $\mathrm{hM} 3 \mathrm{Dq}$ and hM4Di signaling through their downstream $\mathrm{Ga}_{\mathrm{q}}$ protein or $\mathrm{Ga}_{\mathrm{i}}$ protein intracellular pathways, culminating in neuron activation or neuron inhibition (in part through increased inward rectifier $\mathrm{K}^{+}$channel conductance), respectively.
Distinct regulation of acute and long-term control over appetite has been found with manipulation of molecularly defined cell types and circuits. Within the ARC, AGRP neurons are intermingled with POMC neurons that release the neuropeptide $\mathrm{a}-\mathrm{MSH}$, which has been shown to strongly suppress food intake. Cell type-specific POMC neuron activation over $24 \mathrm{~h}$ showed reduced body weight and food intake $[9,17]$, and POMC neuron inhibition correspondingly increased food intake over 24 $\mathrm{h}$ [11]. AGRP neurons form local inhibitory synaptic connections onto POMC neurons [18], indicating a possible circuit through which AGRP neurons can influence appetite. In addition, functional studies have demonstrated that this interaction powerfully suppresses POMC neuron firing when AGRP neurons are activated [11]. However, neither POMC neuron gain-of-function nor loss-offunction manipulations significantly affected food intake over the 1-hour timescale associated with voracious AGRP neuron-evoked food intake $[9,17,19]$. The mismatch in the timescales for AGRP and POMC neuron control over feeding indicated a role for POMC neurons in long-term regulation of appetite and also that AGRP neurons likely do not control acute induction of feeding behavior through suppression of POMC neuron activity.

This was confirmed with neural circuit epistasis analysis in which AGRP neurons were photostimulated simultaneously with POMC neurons [11]. In this experiment, AGRP inhibition of POMC neurons was overcome by coincident depolarization of POMC neurons with channelrhodopsin-2 to test the necessity of this inhibitory interaction for acute control over food consumption. Mice consumed as much food with AGRP neuron activation alone as they did with coactivation of AGRP and POMC neurons [11], consistent with the conclusion that $\mathrm{ARC}^{\mathrm{AGRP}} \rightarrow \mathrm{ARC}^{\mathrm{POMC}}$ does not regulate short-term food intake. Together with the long timescale for POMC neuron activation and silencing to affect food intake, this indicates that AGRP neuron inhibition of POMC neurons may be important for long-term regulation of appetite but not necessarily for the short-term feeding behavior that is elicited upon activation of AGRP neurons.

\section{Neural Circuits That Rapidly Elicit Food Seeking and Consumption Behavior}

The second-order circuit nodes through which AGRP neurons influence behavior and physiology can be visualized by their axon projections using immunochemistry
Sternson/Atasoy 
Fig. 3. Compensatory adaptations in $\mathrm{ARC}^{\mathrm{AGRP}} \rightarrow \mathrm{PVH}$ circuit in $\mathrm{N}^{\mathrm{P} y^{-/-}}$mice. a Observed connectivity rate of the $\mathrm{ARC}^{\mathrm{AGRP}} \rightarrow \mathrm{PVH}$ projection in $N p \mathrm{y}^{+/+}$and $N p y^{-/-}$mice. b, c Representative whole-cell voltage clamp recordings showing paired pulse depression of ARC ${ }^{\text {AGRP }} \rightarrow \mathrm{PVH}$ synapses in $N p y^{+/+}$and $N p y^{-/-}$mice (b) and the average paired pulse response (c). Increased paired pulse depression in $N p y^{-/-}$ mice indicates increased GABA release probability. $A_{1}=$ Amplitude of first pulse; $\mathrm{A}_{2}=$ amplitude of second pulse. Data is represented as mean \pm SEM and is from Atasoy et al. [11].

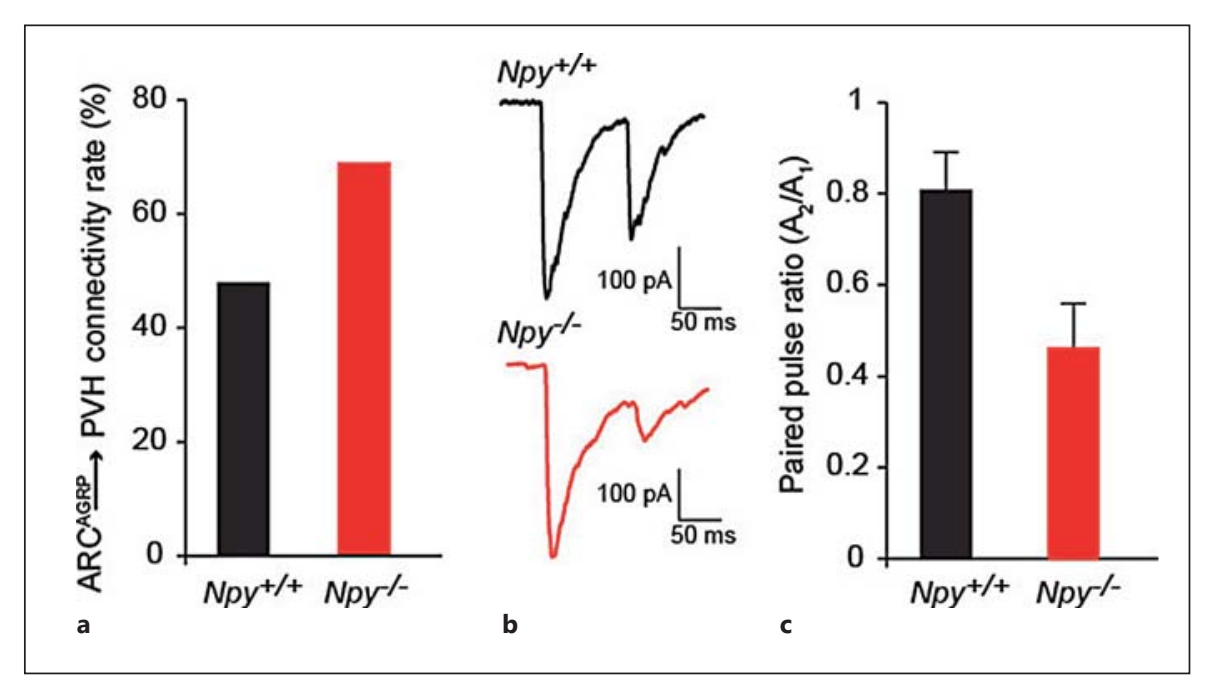

for the neuropeptide AGRP [20] or transgenic expression of a fluorescent protein $[19,21]$. The long-range neural circuit connections of AGRP neurons that mediate acute elevation of appetite have been investigated by optogenetic activation of axon projections $[11,21]$ (fig. 1). These studies identified the anterior portion of the bed nucleus of the stria terminalis (aBNST), the lateral hypothalamus suprafornical division (LHAs), and the $\mathrm{PVH}$ as sufficient to increase food intake to a level similar to that achieved by activation of AGRP neuron somata. Activation of AGRP neuron projections to the paraventricular thalamus (PVT) modestly increased food intake. Axon projections to the central nucleus of the amygdala (CEA), periaqueductal gray (PAG), and parabrachial nucleus (PBN) did not elicit increased food intake. Therefore, a subset of brain areas contacted by AGRP neuron projections is sufficient to induce food consumption behavior. Two of these brain areas, the PVH [22] and the LHA [2], had already been extensively investigated for the feeding behaviors evoked; however, the importance of the LHAs subdivision had only been proposed based on anatomical connectivity [23]. In addition, injection of a $\mathrm{GABA}_{\mathrm{A}}$ receptor agonist into the PVT was found to acutely increase feeding [24]. The BNST had been implicated in obesity based on a lesion study [25], but the role of the anterior subdivisions of the BNST to acutely regulate feeding behavior had not been shown. Therefore, analysis of the axon projections of AGRP neurons enabled identification of a subset of brain areas that were sufficient to elicit food intake.

In addition to functional studies, anatomical analysis of AGRP neuron axon projections has also provided important insights into the organization of feeding circuits.
Individual axon projection fields appear to arise from distinct subpopulations of AGRP neurons, and axon collateralization was not detected [21]. Therefore, molecularly defined AGRP neurons can be subdivided into separate populations defined by their axon projection targets (fig. 1). It is a configuration that is seen in some neuromodulatory systems, such as midbrain dopamine neurons [26], but not in other populations, such as noradrenergic cells in the locus coeruleus [27]. This is suggestive of specialized roles for these distinct AGRP neuron circuits. One example of this comes from the analysis of leptin receptor (Lepr) expression as detected by a LeprIRES-Cre mouse line, which indicated that AGRP neurons that project outside of the hypothalamus express leptin receptor, while those that project within the hypothalamus do not [21]. In contrast, responsiveness to ghrelin or to food deprivation was observed in both intrahypothalamic and extrahypothalamic AGRP neuron projection subpopulations.

Because AGRP neuron axon projections arise from separate neuronal subpopulations, their activation individually identifies target areas that are independently sufficient to initiate feeding (aBNST, LHAs, PVH, and PVT). Nevertheless, anatomical analyses have shown substantial interconnectivity between these brain areas, indicating a network across which feeding may be coordinated. For example, optogenetic activation of GABA-releasing BNST neurons (BNST ${ }^{\mathrm{GABA}}$ ) elicits voracious eating [28]. Using optogenetic circuit mapping in conjunction with single-cell RT-PCR, this was found to involve an inhibitory synaptic projection to the LHA that selectively targets glutamate neurons (fig. 1). Consistent with this, 
LHA ${ }^{\text {glutamate }}$ neuron inhibition evokes feeding [28]. However, the precise relationship to AGRP neuron projections is not yet clear. Although the BNST and LHA neuronal manipulation covered broad areas of each region, the targeted areas were both posterior relative to the respective AGRP axon projection fields targeted for photostimulation (fig. 1). Further work is required to establish the relationship between $\mathrm{ARC}^{\mathrm{AGRP}} \rightarrow \mathrm{aBNST}$, $\mathrm{ARC}^{\mathrm{AGRP}} \rightarrow \mathrm{LHAs}$, and $\mathrm{BNST}^{\mathrm{GABA}} \rightarrow \mathrm{LHA}^{\text {glutamate }}$ circuit elements.

The PVH is another brain area that has a well-established role in regulating feeding behavior [29], and activation of GABA-releasing AGRP neuron axons in the PVH robustly evoked feeding [11]. Cell type-specific chemogenetic neuronal silencing of SIM1 neurons in the PVH (encompassing most $\mathrm{PVH}$ neurons) also rapidly increased eating as well as instrumental food seeking behavior [11]. Interestingly, a recent study has shown that a subset of PVH neurons that express thyrotropin-releasing hormone (TRH) and release glutamate from synaptic contacts onto AGRP neurons can activate food intake [30]. Because silencing the PVH elicits eating (and this likely includes the TRH subpopulations that project to AGRP neurons), it indicates that the PVH circuit responsible for orchestrating feeding behavior also involves $\mathrm{PVH}$ axon projections elsewhere in the brain. To identify this projection, a cell typespecific chemogenetic synaptic silencing tool, based on an axon-selective variant of the $\mathrm{Ga}_{\mathrm{i}}$ protein-coupled hM4D receptor (fig. 2c), has been used to examine downstream $\mathrm{PVH}$ axon projections for the regulation of appetite. This study found that PVH inhibition acts to increase food intake through projections to the region around the caudal ventrolateral PAG and dorsal raphe [31] (fig. 1). Further experiments are required to determine the underlying cell types in these areas that control appetite.

\section{Neural Circuits for Anorexia}

One of the striking characteristics of AGRP neurons is that their rapid ablation in adult mice leads to anorexia, ultimately resulting in death by starvation [12]. Although this was first attributed to the important role of AGRP neurons to positively regulate appetite, further investigation has revealed that suppression of eating may be due to a function of AGRP neurons that is distinct from the process by which these neurons acutely elicit voracious food intake. Using localized intracranial injections of benzodiazepines $\left(\mathrm{GABA}_{\mathrm{A}}\right.$ receptor potentiators), it was found that infusion into the $\mathrm{PBN}$ restored feeding in mice after AGRP neuron ablation, and this was not seen in other areas, such as the PVH [32]. Therefore, AGRP neuron projections to the $\mathrm{PBN}$ appear to play an essential role for maintaining appetite through their release of GABA. In light of this, it was surprising when activation of AGRP axon projections to the $\mathrm{PBN}$ did not elicit feeding in the same manner as the ARC ${ }^{\mathrm{AGRP}} \rightarrow \mathrm{PVH}$ projection did [11]. However, the distinction between these two pathways has become increasingly clear with further analysis of the PBN appetite regulatory circuit, which appears to be a visceral malaise anorexia circuit and not an acute activator of voracious eating.

Using rescue of AGRP neuron ablation-induced anorexia as a readout, a series of hindbrain manipulations was identified that restored eating in mice lacking AGRP neurons. These experiments revealed a circuit from hindbrain serotonin neurons to serotonin receptor 3 (5HT3 receptor)-expressing neurons in the nucleus of the solitary tract (NTS) that, in turn, activates glutamatergic NTS neurons that project to the PBN [33] (fig. 1). The involvement of 5HT3 receptor signaling in the NTS and a finding that the antiemetic ondansetron (a 5HT3 receptor antagonist) restored eating after AGRP neuron ablation indicated that this circuit may also be activated by signals that lead to nausea. Indeed, further investigation has shown that a subset of PBN neurons that express the peptide calcitonin gene-related peptide (CGRP) mediate the response to many signals associated with nausea or illness and are known to suppress appetite [34]. Activation of $\mathrm{PBN}^{\mathrm{CGRP}}$ axon projections to the CEA but not to the BNST strongly reduces appetite [34]. Moreover, silencing PBN ${ }^{\text {CGRP }}$ neurons leads to modest reduction in anorexia due to nausea agents such as $\mathrm{LiCl}$; however, basal food intake is not elevated [34]. Furthermore, a recent report found that neurons that express protein kinase $\mathrm{C}-\delta$ $\left(\mathrm{PKC}-\delta^{+}\right)$in the lateral division of CEA are likely responsible for the anorexigenic effect of PBN ${ }^{\text {CGRP }}$ activation [35]. PKC- $\delta^{+}$neurons receive direct synaptic input from PBN ${ }^{\text {CGRP }}$ neurons. Moreover, increasing PKC- $\delta^{+}$neuron activity robustly reduced food intake, whereas inhibition of these neurons modestly increased food intake [35]. A local inhibitory connection made by $\mathrm{PKC}-\delta^{+}$neurons onto other CEA neurons (PKC- $\left.\delta^{-}\right)$likely mediates this effect, although the precise molecular identity of these PKC- $\delta^{-}$neurons remains to be determined [35].

What then is the role of the $\mathrm{ARC}^{\mathrm{AGRP}} \rightarrow \mathrm{PBN}$ projection? It appears that a visceral malaise anorexia circuit involving $\mathrm{RMg}^{5 \mathrm{HT}} / \mathrm{ROb}^{5 \mathrm{HT}} \rightarrow \mathrm{NTS}^{5 \mathrm{HT} 3 \mathrm{R}} \rightarrow$ $\mathrm{PBN}^{\text {glutamate }(\mathrm{CGRP})} \rightarrow \mathrm{CEA}^{\mathrm{GABA}(\mathrm{PKC}-\delta+)} \rightarrow \mathrm{CEA}^{\mathrm{PKC}-\delta-}$ suppresses appetite and is modulated by AGRP neurons 
(fig. 1). The loss of the ARC ${ }^{\mathrm{AGRP}} \rightarrow \mathrm{PBN}$ inhibitory input appears to upset the excitatory/inhibitory balance in PBN neurons that mediates anorexia related to circulating and neural signals associated with visceral malaise. Therefore, $\mathrm{ARC}^{\mathrm{AGRP}} \rightarrow \mathrm{PBN}$ axon projections play an essential role for gating visceral inputs and suppressing a visceral malaise state that causes anorexia. It will also be important to investigate the possibility of a similar role for the $\mathrm{ARC}^{\mathrm{AGRP}} \rightarrow \mathrm{CEA}$ circuit, which was not found to evoke food intake [21], but it may be positioned to gate the anorexigenic output of the CEA.

\section{Conclusions}

Overall, the emerging picture is that AGRP neurons influence appetite through multiple processes. Based on investigations with cell type-specific and projection- specific manipulations, these include (1) long-term regulation of feeding behavior through POMC neurons, (2) acute control of appetite through an interconnected 'core forebrain feeding circuit' [21] involving aBNST, PVH, LHAs, and the PVT, and (3) gating of visceral signals that include those associated with illness and nausea. It is noteworthy that nearly all of the brain regions associated with long-term feeding, acute appetite, or visceral malaise are also interconnected. Identification of additional cell types, cell type-specific perturbations, and circuit mapping techniques will be needed to elucidate the role of these seemingly distinct but shared networks in regulating different aspects of appetite. Furthermore, access to these different neural circuits will facilitate the understanding of the underlying behavioral mechanisms by which AGRP neurons elicit goal-directed motivated behaviors associated with food seeking [36].

\section{References}

1 Hess WR: The Functional Organization of the Diencephalon. New York, Grune \& Stratton, 1957.

2 Delgado JM, Anand BK: Increase of food intake induced by electrical stimulation of the lateral hypothalamus. Am J Physiol 1953;172: 162-168.

-3 Hetherington AW, Ranson SW: Hypothalamic lesions and adiposity in the rat. Anat Rec 1940;78:149-172.

4 Saper CB, Chou TC, Elmquist JK: The need to feed: homeostatic and hedonic control of eating. Neuron 2002;36:199-211.

5 Gao Q, Horvath TL: Neurobiology of feeding and energy expenditure. Annu Rev Neurosci 2007;30:367-398.

6 Cowley MA: The distribution and mechanism of action of ghrelin in the CNS demonstrates a novel hypothalamic circuit regulating energy homeostasis. Neuron 2003;37: 649-661.

7 van den Top M, Lee K, Whyment AD, Blanks AM, Spanswick D: Orexigen-sensitive NPY/ AgRP pacemaker neurons in the hypothalamic arcuate nucleus. Nat Neurosci 2004;7:493494.

$>_{8}$ Fioramonti X, Contie S, Song Z, Routh VH, Lorsignol A, Penicaud L: Characterization of glucosensing neuron subpopulations in the arcuate nucleus: integration in neuropeptide $\mathrm{Y}$ and pro-opio melanocortin networks? Diabetes 2007;56:1219-1227.

$\checkmark 9$ Aponte Y, Atasoy D, Sternson SM: AGRP neurons are sufficient to orchestrate feeding behavior rapidly and without training. Nat Neurosci 2011;14:351-355.
10 Krashes MJ, Koda S, Ye C, Rogan SC, Adams AC, Cusher DS, Maratos-Flier E, Roth BL, Lowell BB: Rapid, reversible activation of AgRP neurons drives feeding behavior in mice. J Clin Invest 2011;121:1424-1428.

11 Atasoy D, Betley JN, Su HH, Sternson SM: Deconstruction of a neural circuit for hunger. Nature 2012;488:172-177.

12 Luquet S, Perez FA, Hnasko TS, Palmiter RD: NPY/AgRP neurons are essential for feeding in adult mice but can be ablated in neonates. Science 2005;310:683-685.

13 Ollmann MM, Wilson BD, Yang YK, Kerns JA, Chen Y, Gantz I, Barsh GS: Antagonism of central melanocortin receptors in vitro and in vivo by agouti-related protein. Science 1997;278:135-138.

14 Clark JT, Kalra PS, Crowley WR, Kalra SP: Neuropeptide $Y$ and human pancreatic polypeptide stimulate feeding behavior in rats. Endocrinology 1984;115:427-429.

15 Kelly J, Grossman SP: GABA and hypothalamic feeding systems. II. A comparison of GABA, glycine and acetylcholine agonists and their antagonists. Pharmacol Biochem Behav 1979;11:647-652.

16 Krashes MJ, Shah BP, Koda S, Lowell BB: Rapid versus delayed stimulation of feeding by the endogenously released AgRP neuron mediators GABA, NPY, and AgRP. Cell Metab 2013;18:588-595.

17 Zhan C, Zhou J, Feng Q, Zhang JE, Lin S, Bao J, Wu P, Luo M: Acute and long-term suppression of feeding behavior by POMC neurons in the brainstem and hypothalamus, respectively. J Neurosci 2013;33:3624-3632.
18 Cowley MA, Smart JL, Rubinstein M, Cerdan MG, Diano S, Horvath TL, Cone RD, Low MJ: Leptin activates anorexigenic POMC neurons through a neural network in the arcuate nucleus. Nature 2001;411:480-484.

19 Atasoy D, Aponte Y, Su HH, Sternson SM: A FLEX switch targets Channelrhodopsin-2 to multiple cell types for imaging and longrange circuit mapping. J Neurosci 2008;28: 7025-7030.

20 Haskell-Luevano C, Chen P, Li C, Chang K, Smith MS, Cameron JL, Cone RD: Characterization of the neuroanatomical distribution of agouti-related protein immunoreactivity in the rhesus monkey and the rat. Endocrinology 1999;140:1408-1415.

21 Betley JN, Cao Zhen Fang H, Ritola Kimberly D, Sternson Scott M: Parallel, redundant circuit organization for homeostatic control of feeding behavior. Cell 2013;155:1337-1350.

22 Leibowitz SF: Paraventricular nucleus: a primary site mediating adrenergic stimulation of feeding and drinking. Pharmacol Biochem Behav 1978;8:163-175.

23 Hahn JD, Swanson LW: Distinct patterns of neuronal inputs and outputs of the juxtaparaventricular and suprafornical regions of the lateral hypothalamic area in the male rat. Brain Res Rev 2010;64:14-103.

24 Stratford TR, Wirtshafter D: Injections of muscimol into the paraventricular thalamic nucleus, but not mediodorsal thalamic nuclei, induce feeding in rats. Brain Res 2013;1490: 128-133.
AGRP Neuron Circuits That Regulate Appetite
Neuroendocrinology 2014;100:95-102 DOI: $10.1159 / 000369072$ 
25 King BM, Rollins BL, Grundmann SJ, Olivier LG: Excessive weight gains in female rats with transections of the stria terminalis. Physiol Behav 2003;78:563-568.

26 Prensa L, Parent A: The nigrostriatal pathway in the rat: a single-axon study of the relationship between dorsal and ventral tier nigral neurons and the striosome/matrix striatal compartments. J Neurosci 2001;21:72477260.

-27 Simpson KL, Altman DW, Wang L, Kirifides ML, Lin RC, Waterhouse BD: Lateralization and functional organization of the locus coeruleus projection to the trigeminal somatosensory pathway in rat. J Comp Neurol 1997; 385:135-147.

28 Jennings JH, Rizzi G, Stamatakis AM, Ung RL, Stuber GD: The inhibitory circuit architecture of the lateral hypothalamus orchestrates feeding. Science 2013;341:1517-1521.
29 Kelly J, Rothstein J, Grossman SP: GABA and hypothalamic feeding systems. I. Topographic analysis of the effects of microinjections of muscimol. Physiol Behav 1979;23:1123-1134.

30 Krashes MJ, Shah BP, Madara JC, Olson DP, Strochlic DE, Garfield AS, Vong L, Pei H, Watabe-Uchida M, Uchida N, Liberles SD, Lowell BB: An excitatory paraventricular nucleus to AgRP neuron circuit that drives hunger. Nature 2014;507:238-242.

31 Stachniak TJ, Ghosh A, Sternson SM: Chemogenetic synaptic silencing of neural circuits localizes a hypothalamus $\rightarrow$ midbrain pathway for feeding behavior. Neuron 2014;82:797808.

$32 \mathrm{Wu}$ Q, Boyle M, Palmiter R: Loss of GABAergic signaling by AgRP neurons to the parabrachial nucleus leads to starvation. Cell 2009; 137:1225-1234
33 Wu Q, Clark MS, Palmiter RD: Deciphering a neuronal circuit that mediates appetite. $\mathrm{Na}$ ture 2012;483:594-597.

34 Carter ME, Soden ME, Zweifel LS, Palmiter RD: Genetic identification of a neural circuit that suppresses appetite. Nature 2013;503: 111-114.

35 Cai H, Haubensak W, Anthony TE, Anderson DJ: Central amygdala PKC-delta(+) neurons mediate the influence of multiple anorexigenic signals. Nat Neurosci 2014;17:1240-1248.

36 Sternson SM, Nicholas Betley J, Cao ZF: Neural circuits and motivational processes for hunger. Curr Opin Neurobiol 2013;23:353360

37 Fenno L, Yizhar O, Deisseroth K: The development and application of optogenetics. Annu Rev Neurosci 2011;34:389-412.

38 Sternson SM, Roth BL: Chemogenetic tools to interrogate brain functions. Annu Rev Neurosci 2014;37:387-407. 